\title{
A Rare Case of Isolated Cecal Necrosis
}

\author{
Challa Sravani $^{1}$, Madhura M Killedar ${ }^{2}$ \\ ${ }^{1}$ Junior Resident 3, Bharati Vidyapeeth Medical College and Hospital, Sangli, Maharashtra, India. \\ ${ }^{2}$ Professor, General Surgery, Bharati Vidyapeeth Medical College and Hospital, Sangli, Maharashtra, India.
}

Corresponding Author: Challa Sravani

\begin{abstract}
Isolated cecal necrosis is a rare abdominal condition. Usually presents as acute appendicitis clinically. Mostly occurring in older patients with cardiac and renal comorbidities. Anatomical abnormality of cecal blood supply is usually observed. Diagnosis is difficult preoperatively without high degree of suspicion. Any delay in diagnosis can lead to fatal complication.
\end{abstract}

Keywords: isolated cecal necrosis, ischemic colitis, acute appendicitis

\section{INTRODUCTION}

Ischemic colitis results from decreased blood flow to colon mostly due to atherosclerosis of vessels. Ischemic colitis involving only cecum is quite rare usually presenting as right lower abdominal pain. Patient could land in cecal perforation if there is delay in diagnosis.

\section{CASE REPORT}

We report a case of $83 \mathrm{yr}$ female presenting with abdominal pain and vomiting for 8 days. Treatment being taken at local doctor. Sonography done revealed acute appendicitis and so patient was referred to higher center. Patient had history of angioplasty done 5 months ago. On general examination patient had tachycardia and temperature of $100 * \mathrm{~F}$. on abdominal examination tenderness in right hypochondriac region with rebound tenderness present. Clinically suggestive of acute appendicitis patient taken for emergency laparoscopic appendectomy.

Laparoscopy revealed grossly normal appendix and necrosis of cecal wall found. Exploratory laparotomy with lower midline incision was done. Entire colon examined for any stricture's growth or ischemic changes. But rest of colon appeared normal. Limited ileo-colectomy with ileo-ascending colon end to side anastomosis performed. Postoperative recovery of patient was uneventful.

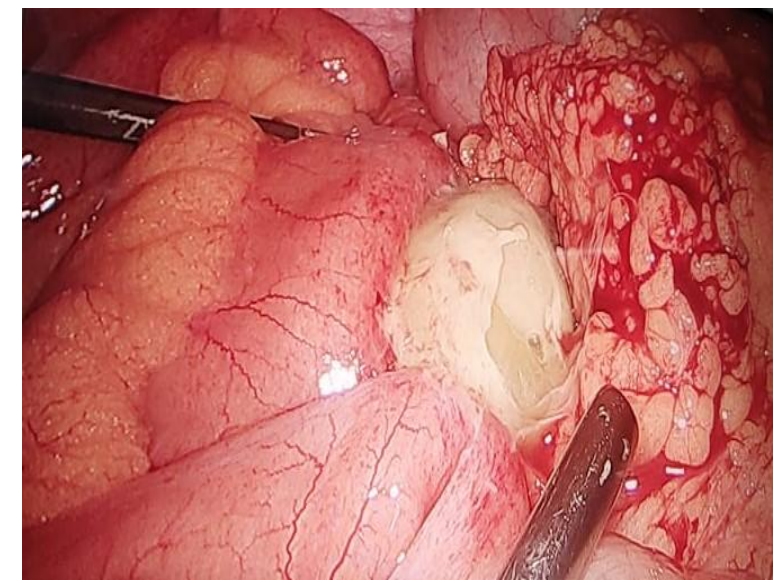

Image 1 ; lump formation with discoloration of cecal wall

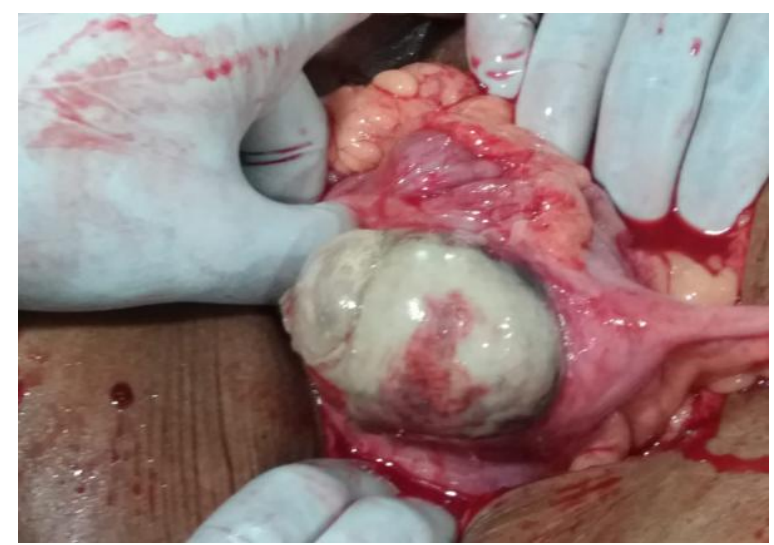

Image 2 : deliering cecum and appendix through laparotomy incision 
Histopathological reports grossly ileal and cecal adhesions. Microscopic changes include ulcerative mucosa with partial necrosis of cecal wall. Areas of

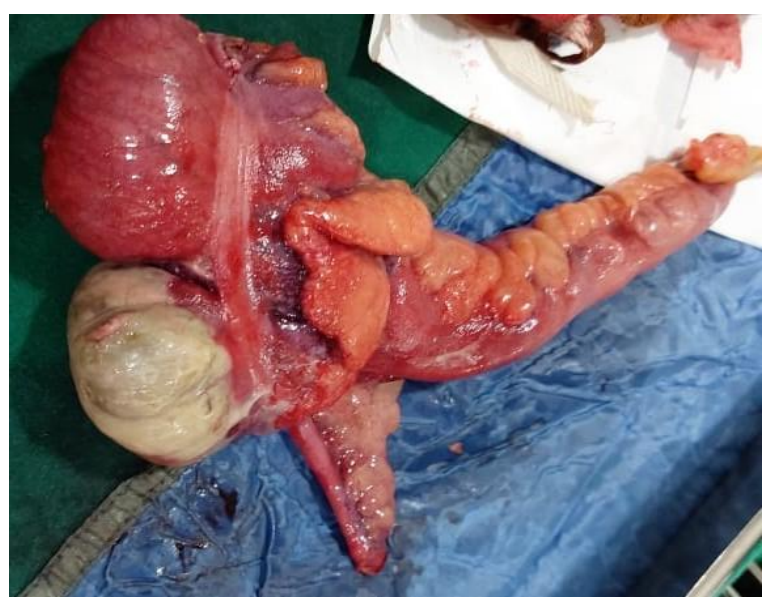

Image 3: image of the specimen dissected (part of ileum, caecum, appendix and part of ascending colon).

\section{DISCUSSION}

Blood supply of caecum is by anterior and posterior caecal arteries arising from the vascular arcade between the ileal branch and colic branch of the ileocolic artery. Caecal blood supply is identified as deficient when this arcade is absent and these arteries arise directly from ileal or colic branches. Wide diameter of caecum also makes it vulnerable for ischemia.

Isolated cecal necrosis could be result due to occlusive or non-occlusive causes. Occlusion of blood supply due to atherosclerosis or embolus. Non occlusive variety most commonly seen among cardiac patients or patients on hemodialysis. also been associated with shock, cardiac failure ${ }^{[1]}$, ischemic heart disease, diabetes and drugs such as cocaine, thiopentone, digoxin ${ }^{[2]}$ and cytotoxic agents.

In nonocclusive $\mathrm{CI}$ in humans, it is thought that a low-pressure vascular state such as shock cause vasoconstriction of intestinal arteries which result in decreased perfusion and necrosis. Hunter et al. suggested that patients who develop ICN may have a particular variation in the caecal blood supply ${ }^{(3)}$.

Bacterial superinfection is a suggested cofactor in the pathogenesis of isolated caecal necrosis. The site of initial ischemia and damage to the mucosal barrier serosal hemorrhage show inflammatory infiltrate. Appendix, ileum and colonic cut margin shows no pathology.

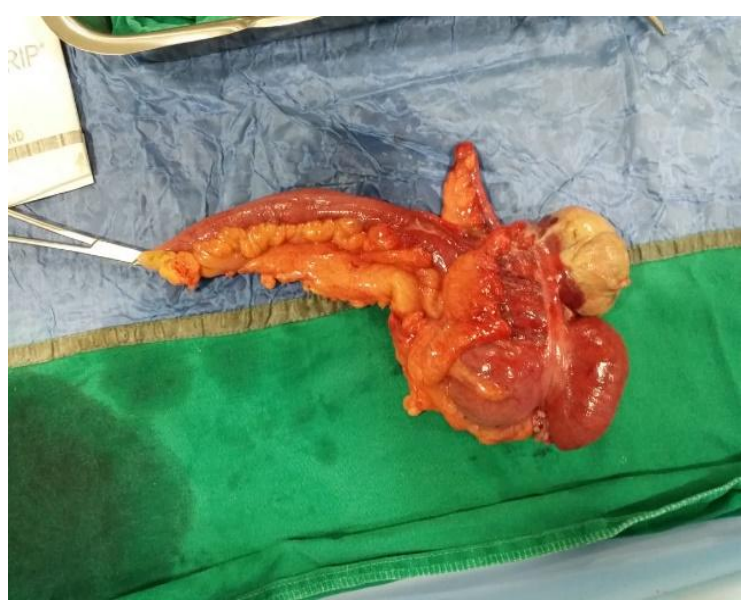

is invaded by bacteria from the caecal lumen. These bacteria, along with inflammatory cells, cause additional damage to the caecal wall, including the microvasculature to propagate the lesion.

ICN presents a diagnostic challenge (4). CT findings are nonspecific, but can help identify any anomaly in vasculature. Diffuse cecal wall thickening is seen in contrast CT scan. Colonoscopy is contraindicated due to risk of perforation. Diagnostic laparoscopy is considered as a useful option to make a definitive diagnosis and to implement a surgical strategy which includes incision type ${ }^{[5]}$.

\section{CONCLUSION}

Among old age patients with cardiac comorbidities presenting with right lower quadrant abdominal pain isolated caecal necrosis should also be considered a differential diagnosis. Early operative intervention could help prevent cecal perforation

Acknowledgement: None

Conflict of Interest: None

Source of Funding: None 


\section{Declaration of Patient Consent}

Appropriate patient consent was taken prior to publication in the journal.

\section{REFERENCES}

1. Schuler, J.G.; Hudlin, M.M. Cecal necrosis: Infrequent variant of ischemic colitis. Report of five cases. Dis. Colon Rectum. 2000, 43, 708-712. [CrossRef] [PubMed]

2. Rist, C.B.; Watts, J.C.; Lucas, R.J. Isolated ischemic necrosis of the cecum in patients with chronic heart disease. Dis. Colon Rectum. 1984, 27, 548-551. [CrossRef] [PubMed]

3. Hunter, J.P.; Saratzis, A.; Zayyan, K. Spontaneous, isolated caecal necrosis: Report of a case, review of the literature, and updated classification. Acta Chir. Belg. 2013, 113, 60-63. [CrossRef] [PubMed]

4. Wiesner W, Mortelé KJ, Glickman JN, Ros PR. 'Cecal gangrene': a rare cause of rightsided inferior abdominal quadrant pain, fever, and leukocytosis. Emerg Radiol. 2002; 9:292-295. [PubMed] [Google Scholar]

5. Perko, Z.; Bilan, K.; Vilovic', K.; Druzijanic', N.; Kraljevic', D.; Juriicic', J.; Krnic', D.; Srsen, D.; Pogorelic', Z.; Tomic',S.Partialcecalnecrosistreatedbylapar oscopicpartialcecalresection. Coll. Antropol. 2006,30,937-939. [PubMed]

How to cite this article: Sravani C, Killedar MM. A rare case of isolated cecal necrosis. Int $J$ Health Sci Res. 2021; 11(6): 197-199. DOI: https://doi.org/10.52403/ijhsr.20210631 